\title{
Nursing Aotearoa New Zealand and the establishment of the National Close Contact Service: A critical discussion
}

\author{
Caz Hales ${ }^{1,2}$, PhD, RN, Senior Lecturer \\ Deborah Harris'2, PhD, NP, Senior Lecturer \\ Helen Rook ${ }^{1,2}$, PhD, RN, Senior Lecturer \\ 1 Joint primary authors \\ 2 School of Nursing, Midwifery \& Health Practice, Te Herenga Waka, \\ Victoria University of Wellington, Wellington, Aotearoa New Zealand \\ Corresponding Authors: caz.hales@vuw.ac.nz; helen.rook@vuw.ac.nz
}

\author{
Citation \\ Hales, C., Harris, D., \& Rook. H. (2021). Nursing \\ Aotearoa New Zealand and the establishment \\ of the National Close Contact Service: A critical \\ discussion. Nursing Praxis in Aotearoa New \\ Zealand, 37(3), 12-14. \\ https://doi.org.10.36951/27034542.2021.041
}

\begin{abstract}
The COVID-19 pandemic has resulted in inestimable morbidity and mortality across the globe. The healthcare and political leadership of the pandemic within Aotearoa New Zealand has been internationally recognised. The pivotal role of nurses and nursing practice in the establishment of National Close Contact Service (NCCS) has been fundamental in protecting the health of our nation. Using exemplars, and the themes of shared human vulnerability and professional authority, this critical discussion draws on theoretical and philosophical nursing perspectives to demonstrate the authors' involvement in the establishment of the NCCS.
\end{abstract}

Keywords: COVID-19; national response; nursing; contact tracing; nursing theory

\section{Introduction}

The COVID-19 pandemic has resulted in inestimable morbidity and mortality across the globe. The healthcare and political leadership of the pandemic within Aotearoa New Zealand has been internationally recognised for its 'going hard and early' elimination strategy (Jamieson, 2020). Central to this strategy was the ability to contact trace at a population level. In March 2020, nurses led the establishment of the National Close Contact Service (NCCS), later known as the National Investigation and Tracing Centre (Cumming, 2021). Nurses were a critical workforce in the Ministry of Health COVID-19 response team. Using exemplars, this critical discussion draws on theoretical and philosophical nursing perspectives to understand how nursing influenced and directed the experiences of the authors' involvement in the establishment of the NCCS. The exemplars presented feature important contextual timepoints experienced by the authors and inform the critical discussion.

\section{Exemplar 1: Shared human vulnerability}

On the 23rd March, 2020, a small team of contact tracers in a room at the Ministry of Health paused calling the public and listened to the Prime Minister announce that New Zealanders had 48 hours to plan and prepare for a national lockdown. The address focused on the necessity to eliminate transmission to protect the New Zealand public from high death rates and an overwhelmed health system that was apparent in Italy. In the room there was a palpable sense of shared human vulnerability and an overwhelming responsibility to act fast. Within five minutes of the announcement nurses returned to calling those of the public who had been in close contact with positive COVID-19 cases.

The sense of urgency and shared vulnerability in this exemplar prompts the question of how to shift psychologically and emotionally from thinking about family and self, to the needs of the public? As nurses we are educationally, experientially, and professionally socialised to cognitively shift from self toward other without hesitation. This well recognised mechanism of compartmentalisation is used to protect a nurse from extreme distress (Menzies, 1960; Rook, 2017). In this case, the extreme distress related to the worry about family, whānau, and friends in light of COVID-19 and the need for nurses to focus on their professional responsibilities and social mandate to keep communities safe. Nurses' 
ability to support the community, in a time of uncertainty, is founded in the trust that the public have in the nursing profession particularly during times of human vulnerability (Dinç \& Gastmans, 2012; Sellman, 2005). This inherent trust was critical to callers being effective in delivering the public health message. This trust is embodied in nursing's Code of Conduct (Nursing Council of New Zealand, 2012) and supported by an unwritten mandate from the public, to deliver safe and effective care and act in a way that has their best interests in mind.

Given the heightened public anxiety about COVID-19 and the uncertainty about the future, especially knowing vaccines were still being developed, many New Zealanders exhibited high degrees of stress (Gasteiger et al., 2021). As nurses we employed what Meehan (2012, p.2910) describes as "contagious calmness" during the COVID-19 calls to the public to establish the emotional tone of the conversations. Contagious calmness is reflected in nurses' attitudes and "quiet dependability" and "alertness" to counter anxieties that arose during these phone calls as the pandemic evolved. We noticed that the nurse's tone of voice and skilled communication offered reassurance and from our perspective, engendered public trust.

\section{Exemplar 2: Professional authority}

Within one week of setting up NCCS the size of the team expanded exponentially from a handful of key personnel on the first day to up to 50 contact trace callers. Most of these callers were nurses and worked as part of the operations team within the larger COVID-19 response team. In the first few days the operations team was operating from an excel spreadsheet but within six days had moved to an evolving online national contact tracing system. The call centre team were required to learn new systems and processes. Sometimes these systems and processes changed multiple times a day as new information became available. Education and training were ongoing as staff were being orientated to the role daily as the need of the NCCS expanded.

Nurses took professional authority and leadership in the NCCS space to develop a high standard of service that was undertaken with professional selfconfidence. For example, in supporting members of the public who were identified as close contacts, the authors participated in the development of the first call scripts and the 'three phone call' approach used to provide public health guidance regarding selfisolation and infection control measures. This was done to standardise the messaging for the public and the clinical team, to reduce error and for auditing and data collection. These 'scripts' were regularly revised as new information became available.

Our self-confidence in this space was founded in our understanding of how health systems work, population health, and how to communicate effectively. During our time working in the NCCS the authors used their knowledge to work in partnership and collaborate across government agencies such as Ministry of Business Innovation and Employment, Ministry of Justice, Ministry of Social Development, Public Health Units, District Health Boards, Primary Health Care and with members of the public. Nurses were involved in strategic and policy development across the whole NCCS, tested the National Contact Tracing System (data management system), provided mentorship to staff within the call centre, and actively supported each other. The reality of the work was situated in uncertainty, "a lack of sureness" about what was ahead, primarily driven by the complexity of the evolving situation (Begun \& Kaissi, 2005, p.109) and current lack of scientific evidence. However, the uncertainty was not debilitating for the nursing team who were used to working in changeable and complex healthcare systems.

These activities undertaken by nurses were guided by shared professional values and professional identity as they enacted the nursing process. Nurses assessed the situation, considered the information, diagnosed (identified the nature of the problem; not enough data, welfare concerns, cultural needs etc), planned in partnership to determine what was needed, implemented the plan, and evaluated regularly. One issue identified early on was the need to support families with welfare needs as a direct consequence of self-isolation requirements. These welfare needs ranged from financial support due to loss of earnings, enabling contactless food and medicine deliveries in geographically remote areas and transportation to COVID-19 testing stations. This required the nursing team to systematically map out the referral process, and to lead administrative processes that integrated with existing systems used by multiple government and non-government agencies. The aim being to embed failsafe processes 
that ensured welfare support was delivered in a timely manner. Orlando's (1972) deliberative nursing process theory emphasises the importance of the reciprocal relationship between the patient and nurse. Even though in this instance nurses were not liaising with patients per se, the principles of reciprocity, and the identification of needs were key in their critical thinking, moral reasoning and decision making. Ultimately this guided nurses to a rational examination of the presented data and analysis to draw conclusions and alternatives particularly in the presence of uncertainty.

This critical reflection draws attention to the theoretical and philosophical perspectives of nursing and how it influenced the nursing workforce in the development, organisation, and management of the NCCS. These exemplars showcase the skills, knowledge and scholarship required to respond to and protect the community and country during a rapidly evolving global health crisis.

\section{References}

Begun, J. W., \& Kaissi, A. A. (2005). 11: The social construction of uncertainty in healthcare delivery. In R. R. McDaniel \& D. J. Driebe (Eds.), Uncertainty and surprise in complex systems: Question on working with the unexpected (pp. 109-121). Springer. https://doi.org/10.1007/10948637 11

Cumming, J. (2021). Going hard and early: Aotearoa New Zealand's response to Covid-19. Health Economics, Policy and Law, 1-13. https://doi.org/10.1017/S174413312100013X

Dinç, L., \& Gastmans, C. (2012). Trust and trustworthiness in nursing: An argument-based literature review. Nursing Inquiry, 19, 223-237. https://doi.org/10.1111/j.1440-1800.2011.00582.x
Gasteiger, N., Vedhara, K., Massey, A., Jia, R., Ayling, K., Chalder, T., Coupland, C., \& Broadbent, E. (2021). Depression, anxiety and stress during the COVID-19 pandemic: Results from a New Zealand cohort study on mental well-being. BMJ Open, 11(5), 1-16. http://dx.doi.org/10.1136/bmjopen-2020-045325

Jamieson, T. (2020). "Go Hard, Go Early": Preliminary lessons from New Zealand's response to COVID-19. The American Review of Public Administration, 50, 598-605. https://doi.org/10.1177/0275074020941721

Meehan, T. C. (2012). The careful nursing philosophy and professional practice model. Journal of Clinical Nursing, 21, 2905-2916. https://doi.org/10.1111/j.1365-2702.2012.04214.x

Menzies, I. (1960). A case-study in the functioning of social systems as a defence against anxiety: A report on a study of the nursing service of a general hospital. Human Relations, 13, 95-121. https://doi.org/10.1177/001872676001300201

Nursing Council of New Zealand. (2012). Code of Conduct for nurses. Author.

Orlando, I. J. (1972). The discipline and teaching of nursing process (an evaluative study). Putnam.

Rook, H. (2017). Living nursing values: A collective case study [Unpublished doctoral thesis, Victoria University of Wellington].

https://researcharchive.vuw.ac.nz/xmlui/bitstream/h andle $/ 10063 / 6358 /$ thesis access.pdf?sequence $=1$

Sellman, D. (2005). Towards an understanding of nursing as a response to human vulnerability. Nursing Philosophy, 6, 2-10. https://doi.org/10.1111/j.1466769X.2004.00202.X

Funding: None

Conflicts of interest: All authors worked at the Ministry of Health during the establishment of the Ministry of Health COVID-19 NCCS. The first author continues to work for the COVID Directorate in the role of Operations Lead. 